\title{
FREQUENCY AND INTENSITY OF GRAZING AND THEIR EFFECTS ON PASTURE PRODUCTION
}

\author{
Grasslands Division, DSIR, Palmerston North
}

IN New Zealand, as in a number of other pastoral areas ur the world, controversy has surrounded the value of pasture management studies using indices such as dry matter production as an aid to predicting possible animal production levels per unit area. This stems from the fact that investigators studying the significance of different frequencies and intensities of grazing on pasture production and species productivity have been able to demonstrate very large differences in herbage production levels, whereas animal production studies using parameters of animal production as indices in these same environments have frequently failed to reflect such large differences. This is in spite of the fact that the extra production obtained in the pasture studies is frequently of high quality and is a very desirable feed for livestock.

This hiatus has been particularly evident in New Zealand for the past twenty years or so. Pasture experimenters have, for instance, predicted annual dairy production levels as high as 750 to $1,000 \mathrm{lb}$ of butterfat per acre when extrapolating from pasture production data, whereas animal production studies have failed to exceed consistently $600 \mathrm{lb}$ of butterfat per acre and, as recently as ten years ago, to exceed consistently $450 \mathrm{lb}$ of butterfat per acre.

The fact that, in ten years, ceiling butterfat yields obtained under experimental conditions have increased by approximately one-third and that these increases have been achieved through inputs based largely on changed pasture management procedures, together with the development of systems of management that utilize the additional feed produced more efficiently, has helped to resolve this hiatus. The pasture experimenters are now a little more convinced that their results are meaningful in terms of farming practice and the animal production experimenters are increasingly placing more emphasis on comparisons of management systems designed to maximize pasture production both in terms of growing more grass per unit area and in 
more efficient utilization of the additional feed produced.

With this background, a few examples of the significance of various management procedures on pasture production levels will be given. Emphasis will be placed on the effect of different frequencies and intensities of grazing on subsequent production levels during periods of the year when feed demands by livestock are frequently greater than those normally produced by pasture - i.e., during the winter and summer-early autumn. Further, most of the results shown will be as they apply to Lolium/Trifolium pastures in environments similar to that of Palmerston North.

\section{SUMMER EFFECTS}

In most farming districts of New Zealand, the production of feed from pastures over the summer frequently falls below stock requirements. It is over this period that marked differences in pasture production can be obtained by the application of different frequencies and intensities of grazing.

The results presented in Fig. 1 illustrate this point. Shown are the yields obtained from two pastures that received similar management for eighteen months prior to late November. In early December, one pasture was grazed hard, then, at approximately three-week intervals, received two more grazings of a similar intensity. The second pasture was grazed just as frequently as the first, but at each of the three summer grazings a stubble height of approximately 3 in. was left. From early February until late September both pastures were then grazed to maximize production. As can be seen, the effects of the three hard

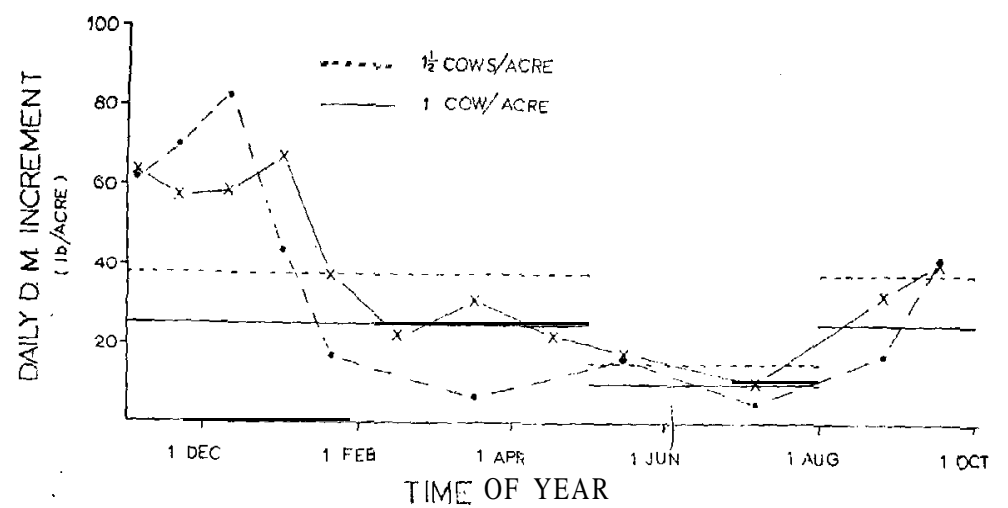

FIG. 1: The effect of summer hard-grazing on subsequent pasture production. 
grazings over the summer had very significant effects on pasture production in the following seven to eight months. When placed beside approximate dairy cow requirements at one and one and a half milking cows per acre, the significance of the depressed yields becomes even more apparent. In the Palmerston North environment, a result such as this is mainly attributable to interactions between grazing pressure, soil moisture levels as influenced by herbage cover, the proportion of tillers of grass plants in the pasture community with growing points above defoliation height, and the persistence of species in the community.

Two of these factors are illustrated in Table 1 and Fig. 2.

Table 1 shows soil moisture profiles (expressed as a percentage of dry soil) under two pastures that received similar treatments to those shown above in February. Shown is an approximate $25 \%$ increase in soil moisture content in the top 3 in of soil under pasture where herbage cover was maintained.

TABLE 1: SOIL MOISTURE PROFILES

(\% of dry soil)

\begin{tabular}{ccc}
\hline $\begin{array}{c}\text { Soil Depth } \\
\text { (in.) }\end{array}$ & $\begin{array}{c}\text { Tightly } \\
\text { Grazed }\end{array}$ & $\begin{array}{c}\text { Herbage Cover } \\
\text { Maintained }\end{array}$ \\
\hline $5-3$ & 14.5 & 18.0 \\
$3-6$ & 16.4 & 17.9 \\
$6-9$ & 17.5 & 18.8 \\
$9-12$ & 17.4 & 18.6 \\
\hline
\end{tabular}



FIG. 2: Proportions of tillers in ryegrass variety pastures with growing points above two levels. 
Figure 2 illustrates the susceptibility of tillers of two ryegrass varieties to hard grazings in the summer. From late October until late December, both ryegrass varieties are shown to have a relatively large number of tillers with growing points susceptible to trampling or eating by stock, particularly when hard grazed.

In dry summers the above effects become dominant, and as shown in Fig. 1 they can markedly affect production levels in subsequent seasons.

\section{WINTER EFFECTS}

The other period of feed shortage in most New Zealand environments is the late autumn, winter and early spring.

Table 2 illustrates the effect of spelling interval over this period on total herbage yields obtained from a grass/clover pasture. The starting date for each treatment was April 3 .

TABLE 2: LATE AUTUMN AND WINTER GRASS YIELDS

\begin{tabular}{cc}
\hline Type of Management & $\begin{array}{r}\text { Total Yields } \\
\text { (1b DM } / \text { acre })\end{array}$ \\
\hline Spelled for 18 weeks & 2,120 \\
Two spells of 9 weeks & 3,290 \\
Three spells of 6 weeks & 3,620 \\
\hline
\end{tabular}

The first treatment corresponds to the situation often seen in practice where stock are wintered-off, whereas the third treatment is the type of management approached by town milk suppliers. An approximate $70 \%$ increase in total yield is shown for the treatment more frequently defoliated. Not shown are the marked increases in clover content that will occur under the more frequently defoliated treatment because of increased illumination in the base of the pasture, thus enhancing subsequent spring growth.

TABLE 3: SEASONAL YIELDS (lb DM/acre) FROM WINTER AND SUMMER HARD-GRAZED PASTURES

\begin{tabular}{lccccc} 
& Winter & Spring & Summer & Autumn \\
\hline Winter & -hard-grazed & 1,760 & 4,750 & 4,560 & 2,280 \\
Summer & hard-grazed & 910 & 4,870 & 1,990 & 970 \\
\hline
\end{tabular}




\section{COMPARISON OF WINTER AND SUMMER HARD GRAZING}

Table 3 compares the effect of hard grazing in the winter and summer. Shown are seasonal yields from a pasture that was grazed hard three times over the winter compared with seasonal yields from a pasture that was grazed hard three times over the summer. For the remainder of the year, both pastures received similar management. Except for the spring, the winter hard-grazed pasture outyielded that grazed hard during the summer by a factor of approximately 2 .

The annual total and species yields from these pastures are shown in Table 4.

TABLE 4: ANNUIAL AND SPECIES YIELDS (lb DM/acre) FROM WINTER AND SUMMER HARD-GRAZED PASTURE

\begin{tabular}{llrrrrrrr}
\hline & & Total & \multicolumn{3}{c}{$\begin{array}{c}\text { Cocks- } \\
\text { Ryegrass foot }\end{array}$} & $\begin{array}{c}\text { Rea } \\
\text { Clover Clover }\end{array}$ & $\begin{array}{c}\text { White } \\
\text { Cpecies }\end{array}$ \\
\hline Hard-grazed & winter & 13,360 & 7,080 & 2,140 & 2,150 & 1,680 & 310 \\
Hard-grazed & summer & 8,750 & 5,280 & 990 & 900 & 1,240 & 340 \\
\hline
\end{tabular}

Some marked differences in species yields are shown, particularly for the components of ryegrass, cocksfoot and red clover. Total yields for the winter hard-grazed treatment were approximately $50 \%$ higher than those obtained from the summer hard-grazed treatment.

Based on studies such as those outlined above, the grazing system shown in Table 5 outlines the type of management procedures considered desirable for dominant Lolium/Trifolium pastures in environments similar to Palmerston North. Such management procedures frequently produce annual dry matter yields of $16-17,000 \mathrm{lb}$ per acre. A system similar to that outlined is currently being adopted in a beef production experiment at Palmerston North. It considers primarily the plants in the pasture and their requirements. In the first year of the experiment, approximately $850 \mathrm{lb}$ of frozen beef meat per acre has been obtained in a

TABLE 5. MANAGEMENT SYSTEMS FOR LOLIUM/TRIFOLIUM DOMINANT PASTURES

\begin{tabular}{llccccc}
\hline & & Winter & Spring Summer & \multicolumn{2}{c}{ A utum n } \\
\hline Spelling interval (weeks) & $6-8$ & $3-4$ & $4-5$ & Hard-graze: & $4-6$ \\
Grazing intensity (in.) & $1-2$ & $1-3$ & $3-4$ & 1 in. 1-2 * \\
\hline
\end{tabular}


year when the annual rainfall was approximately $20 \mathrm{in}$. The dry matter produced per acre was approximately 12,000 $\mathrm{lb}$ (including hay made) and judging by the meat yields obtained most of the dry matter produced would have been utilized by the animals.

The results presented above illustrate but a few of the effects of frequency and intensity of grazing on pasture productivity. They are similar in kind to results obtained in many environments of the world and demonstrate that marked differences in production levels from pasture and drastic changes in the botanical composition can be induced by single grazings, by altering the frequency of the spelling interval between grazings, or by paying attention to the severity of defoliation at grazing. They also show that there can be marked interactions between season and grazing management procedure, indicating that in most high producing areas of New Zealand no single fixed system of management can be applied to pasture if it is hoped to maximize production from the species in the pasture.

This last point is highly significant when considered in the light of the introductory remarks to this paper. Many experiments designed to illustrate the virtues of improved pasture species, to demonstrate differences between various pasture species, or to elucidate differences between various frequencies and intensities of grazing, pre-determine results when fixed and in some cases arbitrarily defined management procedures are applied,

In the time remaining I should like to comment on this. Most animal production experiments designed to determine production ceilings for a given environment have been carried out by applying designs that have, on the one hand, fixed intervals between grazings (e.g., two-week spelling intervals between grazings versus four-week spelling intervals between grazings), constant severities of grazing (e.g., set-stocking, or a fixed time on each paddock in a rotational management system), or varying stocking rates but with the same pasture management procedures adopted at each stocking rate. Yet such studies are frequently carried out in research environments where agronomic data indicate that at certain times of the year such fixed treatments will have detrimental effects on species productivity, on botanical composition of pastures, and hence subsequent pasture production levels. In other words, many of the treatments applied to grazing experiments fail to recognize interactions that occur between season, management system, animal behaviour and intake patterns, and plant 
performance. Three examples of such types of experiment follow:

(1) Frequently seen in research environments around the the world is the "defined interval experiment". In this type of experiment, animal production is usually measured under treatments where varying intervals of spelling in a rotational grazing system determine the treatments. Such experiments are tidy biometrically and to some are objective in that the experimenter is not called upon to make subjective decisions on pasture or animal management variables. Yet I know of no pasture community in the New Zealand environment that will produce at a maximum by being grazed every two or four weeks throughout the year.

(2) The same criticism can be levelled at the large number of stocking rate trials that are frequently seen in various countries where parameters of animal production are being compared at two, three or four stocking rates without variations in pasture management at the different stocking rates. In these experiments, if the objective is to determine the optimum stocking rate for a given management system such as set-stocking on a three-week rotational grazing system, for instance, then there can be no criticism except that by taking this approach results obtained must have only limited application to farming practice. Such comparisons would have much wider application to practice if pasture management procedures were varied at different stocking rates. To limit animal performance at high stocking rates, as frequently occurs in these experiments because of a pre-determined and fixed pasture management procedure, when agronomic and pasture conservation studies can frequently show ways and means of both increasing and levelling out annual feed production above those determined by such fixed procedures, is in some ways a restrictive approach to research. The need for a better agronomic approach to such studies is frequently seen in research environments.

(3) The third example concerns the type of experiment or investigation where various parameters of animal production are measured as influenced by different grazing systems-e.g., set-stocking versus rotational grazing or rotational grazing systems with variable conservation procedures of feed surpluses. Experiments such as 
these frequently fail to assess differences in utilization of the feed produced from the pastures under study. As will be discussed by A. G. Campbell in a later paper in this session, such differences can be large and can frequently result in a masking of real differences between management treatments.

Further investigations designed to assess the contribution that pasture management can make to raising animal production levels should, in my view, be based on sound agronomic studies where the interactions between the plants in the pasture, their growth patterns throughout the year, there tolerances to grazing pressures at different times of the year, and their compatibility one to another are considered in equal terms to those of the requirements of the stock that graze them. Such studies will also need to assess accurately the feed utilized by the animals if the types of differences illustrated in this paper, attributable to different frequencies of interactions of grazing, are to be fully assessed.

\section{DISCUSSION}

Washko (U.S.A.) asked what fertilizer was used in the system described, or did the author rely only on the animal, through dung and "urine, for the circulation of nutrients. Brougham replied that it was a recent alluvial soil and the only requirement was $3 \mathrm{cwt}$ superphosphate/acre/year. No potash or nitrogen was applied. McQueen suggested that the high production obtained from the pasture indicated that, at his stocking rate, he must be below full utilization at certain times of the year. Brougham said that more conserved material should be used when the pinch occurred under high stocking rates in the summer. It was better to feed it then than in the winter. This year, with the drought, the beef animals had been fed on hay and he would now rely on going through the winter on grass. He stressed that there had to be a change in what is done under high stocking rates so that pastures are given some measure of 'protection. Two of the most highly producing farms in the Manawatu had adopted identical management systems similar to that outlined. Frequency and intensity of grazing could easily be adjusted. 